\title{
Evaluasi Kekuatan Struktur Dermaga Setelah Perkuatan di Pelabuhan Ambon Untuk Proses Unloading Container Crane
}

\author{
Denny Christian Somalinggi*1, Mudrikah ${ }^{2}$, Misliah Idrus $^{1}$ \\ ${ }^{1}$ Departemen Teknik Perkapalan, Fakultas Teknik, Universitas Hasanuddin \\ ${ }^{2}$ Departemen Teknik Arsitektur, Fakultas Teknik, Universitas Hasanuddin \\ Jl. Poros Malino km. 6, Bontomarannu, Kabupaten Gowa, Sulawesi Selatan 92171 \\ *Email: denny.somalinggi@yahoo.com
}

DOI: 10.25042/jpe.052019.xx

\begin{abstract}
Abstrak
Perkuatan Dermaga VI Pelabuhan Ambon dilakukan untuk mengingkatkan kapasitas terpasang Terminal Petikemas Ambon untuk mendukung kegiatan bongkar muat petikemas, PT Pelabuhan Indonesia IV (Persero) telah mengadakan 1 (satu) unit Container Crane (CC 01) dimana saat ini dalam proses persiapan unloading dari kapal ke dermaga, Penelitian ini menyajikan evaluasi terhadap kapasitas elemen struktur dermaga meliputi tiang pancang (steel pipe), balok dan pelat lantai. Evaluasi ini dilakukan dengan mengitung kapasitas terpasang dermaga dengan metode elastis dan ultimate serta menggunakan pendekatan secara Teknis yang dapat diterima secara umum dengan mengacu pada ketentuan baku diantaran SNI (Standard Nasional Indonesia) dan OCDI (Overseas Coastal Development Institute of Japan). Pemodelan struktur dilakukan dengan menggunakan program SAP 2000 V16, dimana model struktur dermaga dibuat sedemikan rupa mendekati kondisi struktur terpasang dengan beban roda didistribusi mengikuti pola rencana kegiatan un-loading. Hasil evaluasi menunjukkan besarnya momen pada posisi balok melintang 86,44 Tm dengan stress ratio 0,713 masih lebih kecil jika dibandingkan dengan kapasitas terpasang yaitu 121,25 Tm, balok Listplank 171,74 Tonm dengan stress ratio 0,9 masih lebih kecil jika dibandingkan dengan kapasitas terpasang yaitu 220,06 Tm, pelat lantai 9,36 Tonm dan stress ration pada tiang pancang 0,798 masih lebih kecil jika dibandingkan dengan kapasitas terpasang yaitu 10,39 Tm.
\end{abstract}

\begin{abstract}
Strength evaluation of pier after restengthening at Ambon Port for unloading container crane process. Strengthening Pier VI of Ambon Port is done to increase the installed capacity of Ambon Container Terminal to support container loading and unloading activities, PT Pelabuhan Indonesia IV (Persero) has held 1 (one) Container Crane unit (CC 01) which is currently in the process of unloading preparations from ships to jetty, This study presents an evaluation of the capacity of quay structural elements including steel pipes, beams and floor plates. This evaluation is done by calculating the installed dock capacity with elastic and ultimate methods and using a technical approach that is generally accepted by referring to the standard provisions between SNI (Indonesian National Standard) and OCDI (Overseas Coastal Development Institute of Japan). Structural modeling is carried out using the SAP 2000 V16 program, where the pier structure model is made in such a way as to approach the condition of the installed structure with the load of the distributed wheel following the pattern of un-loading activity plan. The evaluation results show the magnitude of the moment in the position of the transverse beam $86,44 \mathrm{Tm}$ with a stress ratio of 0,713 is still smaller when compared to the installed capacity of $121,25 \mathrm{Tm}$, Listplank beam 171,74 Ton.m with a stress ratio of 0,9 is still smaller when compared to the installed capacity is $220,06 \mathrm{Tm}, 9,36 \mathrm{Ton} . \mathrm{m}$ floor plate and stress ratio at 0,798 piles is still smaller than the installed capacity of $10,39 \mathrm{Tm}$.
\end{abstract}

Kata Kunci: container crane, kekuatan struktur, Dermaga Ambon

\section{Pendahuluan}

Pelabuhan Ambon merupakan pintu gerbang ekonomi di kawasan Ambon, sehingga harus didukung dengan sarana dan prasarana yang memadai. Dalam Rencana Induk Pelabuhan Nasional, Pelabuhan Ambon merupakan pelabuhan utama yang memegang peranan penting dalam mobilisasi penumpang dan barang antar pelabuhan sekitarnya [1]. Dermaga Pelabuhan Ambon segmen VI merupakan hasil pembangunan dengan menggunakan Sumber Dana Internal Perseroan, dimana saat ini telah dioperasikan untuk kegiatan bongkar muat petikemas dengan menggunakan crane darat maupun crane kapal. 
Arus petikemas yang terus mengalami peningkatan yang ditandai dengan pertumbuhan dari tahun ke tahun rata-rata sebesar 5\% berdasarkan data historis lima tahun terakhir, menunjukkan bahwa dibutuhkan penambahan peralatan bongkar muat untuk meningkatkan kapasitas terpasang sehingga proses bongkar muat dapat berjalan dengan lancar.

Dermaga segmen VI yang ada telah didesain untuk kegiatan operasional petikemas, sehingga PT Pelabuhan Indonesia IV (Persero) mendatangkan 1 unit Container Crane. dalam rangka kegiatan unloading Container Crane tersebut, diperlukan perhitungan struktur dermaga sehingga proses unloading maupun saat beroperasi dapat berjalan dengan aman.

Evaluasi dilakukan terhadap kapasitas elemen struktur dermaga meliputi tiang pancang (steel pipe), balok dan pelat lantai. Evaluasi ini dilakukan dengan menggunakan pendekatan secara Teknis yang dapat diterima secara umum dengan mengacu pada ketentuan baku diantaran SNI (Standard Nasional Indonesia) dan OCDI (Overseas Coastal Development Institute of Japan). Adapun data-data yang digunakan berasal dari spesifikasi teknis, gambar disain, As-built drawing, data teknis dari Container Crane, data stratigrafi tanah dasar dan sumber-sumber terkait lainnya.

Adapun hasil akhir dari analisis ini adalah membandingkan antara kapasitas dari setiap elemen struktur dengan beban yang akan bekerja diatasnya, dimana diharapkan kapasitas dari setiap elemen struktur dermaga harus lebih besar dari beban kerja.

\section{Metode Penelitian}

\subsection{Data Penelitian}

Data struktur yang digunakan adalah model dermaga segmen VI yang telah dilakukan perkuatan (Restrengthening) yaitu sebagai berikut :

- Ukuran : 62,5 x $25 \mathrm{~m}$

- Konstruksi: Beton bertulang

- Pondasi : Steel Pipe

Perhitungan Analisa terhadap kekuatan dermaga dihitung dengan menggunakan data-data hasil pembangunan /As Built Drawing sesuai kondisi di lapangan dengan memperhitungakan beban-beban yang akan bekerja pada saat proses unloading Container Crane atau juga pada saat peralatan tersebut telah beroperasi di dermaga VI Pelabuhan Ambon.

Data Komponen struktur dermaga dapat dilihat pada Tabel 1 [2].

Tabel 1. Dimensi properties struktur dermaga

\begin{tabular}{|c|c|c|}
\hline No & Uraian & Desain \\
\hline \multirow[t]{4}{*}{1} & PROPERTIS MATERIAL & \\
\hline & 1.Tiang Baja & $\mathrm{fy}=235 \mathrm{Mpa}$ \\
\hline & 2.Baja Tulangan & $\mathrm{fy}=400 \mathrm{Mpa}$ \\
\hline & 3.Beton Struktur & $\begin{array}{l}\mathrm{K}-400\left(\sigma \mathrm{bk}{ }^{\prime}=40\right. \\
(\mathrm{kg} / \mathrm{cm} 2)\end{array}$ \\
\hline \multirow[t]{12}{*}{2} & DIMENSI STRUKTUR & \\
\hline & 1.Balok Crane & $140 \times 180$ \\
\hline & 2.Balok Memanjang & $80 \times 100$ \\
\hline & 3.Balok Melintang & $80 \times 100$ \\
\hline & 4.Balok Listplank & $120 \times 160$ \\
\hline & 5.Pelat Lantai & $35 \mathrm{~cm}$ \\
\hline & 6.Pile Cap Balok Crane & $200 \times 170 \times 150$ \\
\hline & 7.Pile Cap Ganda & $190 \times 450 \times 130$ \\
\hline & 8.Pile Cap lainnya & $150 \times 150 \times 130$ \\
\hline & 9.Pipa Baja Crane & $\begin{array}{l}\text { Dia. } 914,4 \mathrm{~mm} \text {, } \\
\text { t. } 14.3 \mathrm{~mm}\end{array}$ \\
\hline & & $\begin{array}{l}\text { Dia. } 711,4 \mathrm{~mm}, \text { t. } 12, \\
\mathrm{~mm}\end{array}$ \\
\hline & & $\begin{array}{l}\text { Dia.609,6mm, t.12, } \\
\mathrm{mm}\end{array}$ \\
\hline
\end{tabular}

Beban diperoleh dari spesifikasi alat Container Crane, dimana berat sendiri struktur sekitar 800 ton, dimana beban tersebut didistribusikan secara merata ke masing-masing roda yng berjumlah sebanyak 32 buah. Khusus pada saat kegiatan unloading yang difungsikan hanya 16 buah roda sehingga masing-masing roda akan memikul beban sebesar 50 ton. Gambaran alat Container Crane yang akan beroperasi serta spesifikasinya dapat terlihat pada Gambar 1 dan 2 dibawah. 


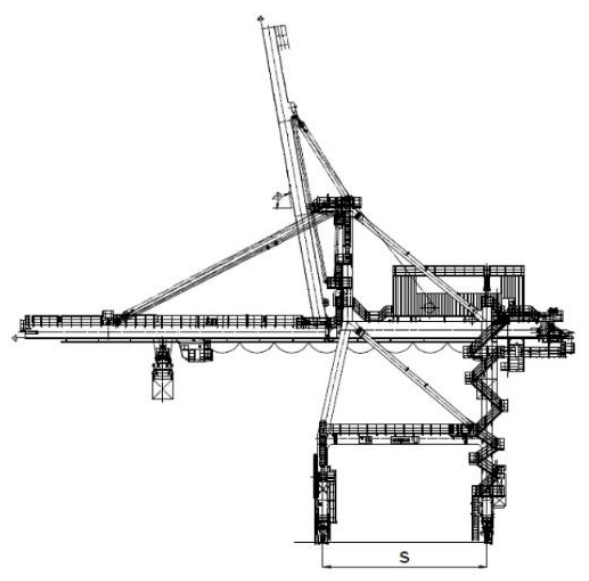

Gambar 1. Tampak Samping Container Crane

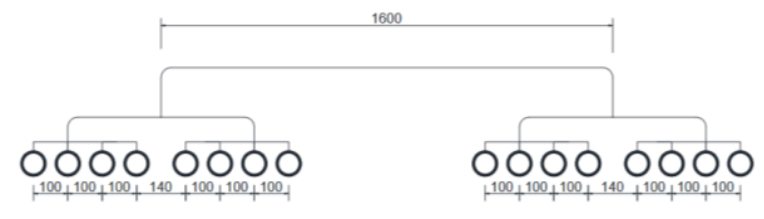

Gambar 2. Konfigurasi Roda Container Crane

Dari Gambar 2 diatas, maka konfigurasi berat dan roda alat sebagai berikut [3]:

- $\quad$ Rail Span $(S)=16 \mathrm{~m}$

- $\quad$ Berat total crane $=800$ ton

- Jumlah roda $=32$ roda

- Jarak minimum antar crane $=10 \mathrm{~m}$

\subsection{Analisis Data}

- Metode Ultimate

Untuk menghitung komponen struktur terhadap beban lentur dan aksial didasarkan pada terpenuhinya kondisi seimbang dan kompabilitas regangan yang berlaku serta asumsi berikut [4] :

- Regangan dalam tulangan dan beton harus diasumsikan berbanding lansung dengan jarak dari sumbu netral.

- Regangan maksimum yang dapat digunakan pada serat beton tekan terluar harus diasumsikan sama dengan 0,003.

- Tegangan dalam tulangan dibawah kuat leleh yang ditentukan fyuntuk mutu tulangan yang digunakan harus diambil sebesar Esdikalikan dengan regangan baja. Untuk regangan yang lebih besar dari regangan yang memberikan fytegangan pada tulangan harus dianggap tidak tergantung pada regangan dan sama dengan fy.

- Dalam perhitungan lentur beton bertulang, kuat tari beton harus diabaikan.

- Hubungan antara distribusi tegangan tekan beton dan regangan beton boleh diasumsikan berbentuk persegi, trapesium, parabola, atau bentuk lain yang menghasilkan perkiraan kekuatan yang cukup baik bila dibandingkan dengan hasil pengujian yang lebih menyeluruh.

- Butir (5) boleh dianggap dipenuhi oleh suatu distribusi tegangan beton persegi ekivalen yang didefenisikan sebagai berikut :

a) Tegangan betonsebesar 0,85fc' harus diasumsikan terdistribusi secara merata pada daerah tekan ekivalen yang dibatasi oleh tepi penampang dan suatu garis lurus yang sejajar dengan sumbu netral sejarak a $=\beta 1 . c$ dari serat dengan regangan tekan maksimum.

b) Jarak c dari serat dengan regangan maksimum ke sumbu netral harus diukur dalam arah tegak lurus terhadap sumbu tersebut.c)Faktor $\beta 1$ harus diambil sebesar 0,85 untuk kuat tekan beton fc' hingga atau sama dengan 30 Mpa. Untuk kekuatan diatas $30 \mathrm{Mpa}, \beta 1$ harus direduksi secara menerus sebesar 0,008 untuk setiap kelebihan 1 Mpa diatas $30 \mathrm{Mpa}$, tetapi $\beta 1$ tidak boleh diambil kurang dari 0,65.

c) Faktor $\beta 1$ harus diambil sebesar 0,85 untuk kuat tekan beton fc' hingga atau sama dengan 30 Mpa. Untuk kekuatan diatas $30 \mathrm{Mpa}, \beta 1$ harus direduksi secara menerus sebesar 0,008 untuk setiap kelebihan 1 Mpa diatas $30 \mathrm{Mpa}$, tetapi $\beta 1$ tidak boleh diambil kurang dari 0,65.

$$
\begin{aligned}
\beta 1= & 0,85 \text { untuk } 0<\mathrm{fc}^{\prime} \leq 30 \mathrm{Mpa} \\
\beta 1= & 0,85-0,008\left(\mathrm{fc}^{\prime}-30\right) \\
& \text { untuk } 30<\mathrm{fc}^{\prime} \leq 55 \mathrm{Mpa} \\
\beta 1= & 0,65 \text { untuk fc' }>55 \mathrm{MPa}
\end{aligned}
$$

\section{- Metode Elastis}

Dalam segala hal, modulus elastisitas sekan beton tidak boleh diambil kurang angka-angka yang didapat dari persamaan berikut : 
- Pada pembebanan tetap

$$
E b=6.400 \sqrt{\sigma^{\prime}} b k \quad\left(\mathrm{~kg} / \mathrm{cm}^{2}\right)
$$

- Pada pembebanan sementara

$$
E b=9.600 \sqrt{\sigma^{\prime}} b k \quad\left(\mathrm{~kg} / \mathrm{cm}^{2}\right)
$$

Tegangan tarik dipikul sepenuhnya oleh baja tulangan, dengan kata lain tegangan tarik pada beton diabaikan. Setiap satuan luas baja tulangan dapat dianggap ekivalen dengan "n"satuan luas beton dalam hal memikul tegangan. Besaran "n"tresebut disebut angka ekivalensi dan ditentukan dengan persamaan berikut :

$$
n=\frac{E_{a}}{E_{b}}
$$

$\mathrm{Ea}=$ modulus elastisitas baja $\left(\mathrm{kg} / \mathrm{cm}^{2}\right)$

$\mathrm{Eb}=$ modulus sekan beton $\left(\mathrm{kg} / \mathrm{cm}^{2}\right)$

Evaluasi kapasitas elemen struktur dermaga dilakukan dengan urutan sebagai berikut :

- Evaluasi dimensi struktur dermaga

- Perhitungan kapasitas penampang beton bertulang dengan metode ultimate dan metode elastis

- Perhitungan kapasitas tiang pancang

- Perhitungan kapasitas tanah dasar

Perhitungan kapasitas penampang beton dihitung dengan metode Elastis dan Metode Ultimate. Struktur dermaga yang dilakukan peninjauan kekuatan yaitu balok $\mathrm{CC}$, balok memanjang, balok melintang, balok listplank dan plat. Dari hasil perhitungan kekuatan struktur maka akan digunakan perhitungan dengan nilai terkecil antara metode ultimate dan metode elastis untuk dibandingkan dengan hasil analisis dengan menggunakan program SAP 2000 yang disimulasi dengan memperhitungkan gaya eksternal yang bekerja.

Kasus masalah struktur yang dapat diselesaikan secara manual dapat dipakai sebagai pembanding dengan hasil solusi computer [5]. Pemodelan struktur dilakukan dengan menggunakan program SAP 2000, dimana model struktur dermaga dibuat sedemikan rupa mendekati kondisi struktur terpasang dengan beban roda didistribusi mengikuti pola rencana kegiatan un-loading. Model pembebanan kondisi ekstrim dibuat pada elemen balok melintang, pelat lantai dan tiang pancang yang akan dilalui saat kegiatan un-loading untuk mendapatkan informasi gaya dalam yang terjadi pada elemen struktur tersebut.

\subsection{Perhitungan Kapasitas Tanah Dasar}

Daya Dukung Tiang Pondasi Berdasarkan Hasil Standard Penetration Test (SPT) dengan Metode Luciano Decourt [6] maka Harga N di bawah muka air tanah harus di koreksi menjadi N' berdasarkan perumusan sebagai berikut:

$$
N^{\prime}=15+0,5(N-15)
$$

Dimana:

$\mathrm{N}=$ Jumlah pukulan kenyataan di lapangan untuk di bawah muka air tanah

$\mathrm{N}^{\prime}=$ Narga $\mathrm{N}$ terkoreksi karena $\mathrm{N}$ dibawah muka air tanah

Kapasitas daya dukung tanah dasar dapat dihitung sebagai berikut :

$$
Q u=Q p+Q s
$$

Dimana:

$\mathrm{Qu}=$ Daya dukung tanah maksimum pada pondasi

Qp = Daya dukung pada dasar pondasi

Qs = Daya dukung akibat lekatan latera

\section{Hasil dan Pembahasan}

Hasil perhitungan kapasitas penampang beton yang dihitung dengan metode Elastis dan Metode Ultimate pada struktur dermaga yaitu balok CC, balok memanjang, balok melintang, balok listplank dan plat dapat dilihat pada tabel berikut:

Tabel 2. Kapasitas penampang beton bertulang (Momen Lentur)

\begin{tabular}{cccc}
\hline \multirow{2}{*}{ Struktur } & Lokasi & $\begin{array}{c}\text { Metode Elastis } \\
\text { (Ton-m) }\end{array}$ & $\begin{array}{c}\text { Metode } \\
\text { Ultimate } \\
\text { (Ton-m) }\end{array}$ \\
\hline \multirow{2}{*}{ Balok CC } & Lapangan & 427,53 & 396,57 \\
\cline { 2 - 4 } & Tumpuan & 427,53 & 396,57 \\
\hline $\begin{array}{c}\text { Balok } \\
\text { Memanjang }\end{array}$ & Lapangan & 131,22 & 121,25 \\
\cline { 2 - 4 } & Tumpuan & 131,22 & 121,25 \\
\hline $\begin{array}{c}\text { Balok } \\
\text { Melintang }\end{array}$ & Lapangan & 131,22 & 121,25 \\
\cline { 2 - 4 } & Tumpuan & 131,22 & 121,25 \\
\hline
\end{tabular}




\begin{tabular}{cccc}
\hline Struktur & Lokasi & $\begin{array}{c}\text { Metode Elastis } \\
\text { (Ton-m) }\end{array}$ & $\begin{array}{c}\text { Metode } \\
\text { Ultimate } \\
\text { (Ton-m) }\end{array}$ \\
\hline $\begin{array}{c}\text { Balok } \\
\text { Lisplank }\end{array}$ & Lapangan & 233,90 & 220,06 \\
\cline { 2 - 4 } Pelat & Tumpuan & 233,90 & 220,06 \\
\cline { 2 - 4 } & Tupangan & 103,87 & 108,15 \\
\hline \multirow{2}{*}{ Tumpuan } & 103,87 & 108,15 \\
\hline
\end{tabular}

Hasil perhitungan metode elastis dan ultimate untuk perhitungan gaya geser dapat dilihat pada Tabel 3 berikut :

Tabel 3. Kapasitas penampang beton bertulang (Gaya Geser)

\begin{tabular}{cccc}
\hline \multirow{2}{*}{ Struktur } & Lokasi & $\begin{array}{c}\text { Metode } \\
\text { Elastis } \\
(\mathbf{k g})\end{array}$ & $\begin{array}{c}\text { Metode } \\
\text { Ultimate } \\
(\mathbf{k g})\end{array}$ \\
\hline \multirow{2}{*}{ Balok CC } & Lapangan & 481,5 & 483,6 \\
\cline { 2 - 4 } & Tumpuan & 481,5 & 483,6 \\
\hline $\begin{array}{c}\text { Balok } \\
\text { Memanjang }\end{array}$ & Lapangan & 144,2 & 144,1 \\
\cline { 2 - 4 } & Tumpuan & 144,2 & 144,1 \\
\hline Balok & Lapangan & 144,2 & 144,1 \\
\cline { 2 - 4 } Melintang & Tumpuan & 144,2 & 144,1 \\
\hline Balok & Lapangan & 363,6 & 364,9 \\
\cline { 2 - 4 } Lisplank & Tumpuan & 363,6 & 364,9 \\
\hline \multirow{2}{*}{ Pelat } & Lapangan & 47,2 & 45,7 \\
\cline { 2 - 4 } & Tumpuan & 47,2 & 45,7 \\
\hline
\end{tabular}

Dari hasil perhitungan momen lentur dan gaya geser tersebut maka digunakan hasil metode ultimit untuk membandingkan dengan perhitungan komputerisasi (SAP 2000).

Evaluasi terhadap kapasitas elemen tiang pancang diperoleh melalui perhitungan SAP 2000 sebagai berikut :

Digunakan baja SKK 400, dengan nilai $\sigma=$ $1400 \mathrm{~kg} / \mathrm{cm}^{2}$---> setara ASTM 252 Grade -2

$\begin{array}{lr}\text { Reaksi CC Pada Tiang } & 157,38 \text { Ton } \\ \text { Beban-beban lainnya } & 47,21 \text { Ton } \\ \text { Beban total } & 204,59 \text { Ton }\end{array}$

Momen yang terjadi 12,19 Ton.m (SAP 2000)

Beban lain-lain 3,65 Ton

Beban total 15,84 Ton

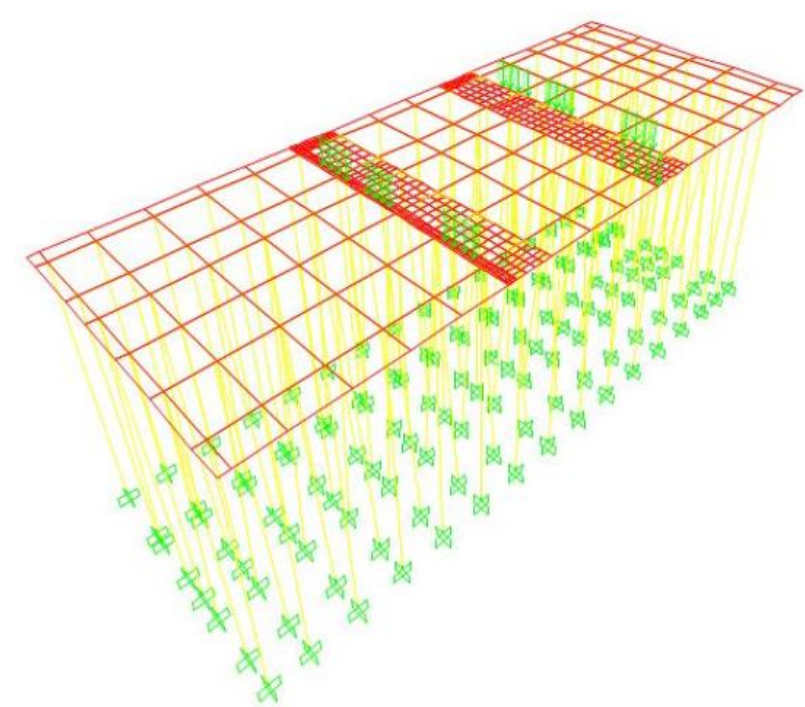

Gambar 3. Permodelan beban Container Crane pada Dermaga

a. Balok Melintang

- Posisi Lapangan

Gaya geser : 38,95 < 144,10

$($ Stress Ratio $=0,270<1,00 \ldots$. OK $)$

Momen : 56,64 < 121,25

$($ Stress Ratio $=0,467<1,00 \ldots$. OK)

- Posisi Tumpuan

Gaya geser : 95,20 < 144,10

$($ Stress Ratio $=0,661<1,00 \ldots$. OK $))$

Momen : 86,44 < 121,25

$($ Stress Ratio $=0,713<1,00 \ldots$. OK $))$

b. Balok Listplank

- Gaya geser Tumpuan : 107,30 < 363,61

$($ Stress Ratio $=0,295<1,00 \ldots$ OK $)$

- $\quad$ Momen posisi Tumpuan : 171,74<220,06

$($ Stress Ratio $=0,780<1,00 \ldots$. OK $)$

c. Pelat Lantai

- Momen posisi Lapangan : 3,67 < 10,39

$($ Stress Ratio $=0,353<1,00 \ldots$ OK)

- Momen posisi Tumpuan : 9,36 < 10,39

$($ Stress Ratio $=0,900<1,00 \ldots$ OK)

d. Tiang Pancang

Stress Ratio $=0,798<1,00 \ldots$ OK

\section{Kesimpulan}

Dari hasil perhitungan tersebut diambil suatu kesimpulan sebagai berikut:

a. Secara umum elemen struktur Dermaga Terminal Petikemas Ambon Cukup Kuat 
memikul beban-beban kerja akibat kegiatan unloading container crane (CC) 01 .

b. Perlu dilakukan perkuatan dan perlindungan pada beberapa elemen struktur, utamanya

c. Permukaan beton lantai dermaga, kansteen yang berpotensi cacat akibat beban titik (crane dan hydraulic jack) pada saat proses unloading dengan memakai plat baja dan karet pada sisisisi beton dermaga.

\section{Referensi}

[1] RIP Pelabuhan Ambon 2018.

[2] PT Pelabuhan Indonesia IV (Persero), 2017, As Bulit Drawing Restrengthening Dermaga VI Pelabuhan Ambon

[3] PT Glory Kasih, 2018, Spesifikasi Teknis Container Crane Jiangsu Gangyi Heavy Machinery Co Ltd

[4] Dipohusodo, I, 1996, Struktur Beton Bertulang, Penerbit PT. Gramedia Pustaka Utama, Jakarta, 544 pp

[5] Wiryanto Dewobroto, 2013. Komputer Rekayasa Struktur dengan SAP 2000, Jakarta

[6] Bowles, J, E, 1991. Analisa dan Desain Pondasi, Edisi Keempat Jilid 2, Erlangga, Jakarta 